\title{
Phospholipase C Gamma
}

National Cancer Institute

\section{Source}

National Cancer Institute. Phospholipase C Gamma. NCI Thesaurus. Code C126114.

A family of phospholipases that are activated by receptor tyrosine kinases, bind to the non-catalytic domains of src-family protein tyrosine kinases, and catalyze the biosynthesis of second messenger signaling molecules. 